\title{
EXTENSÃO VOLTADA AO CAVALO E CARROCEIRO: PROJETO CARROCEIRO - UFPR - PALOTINA E PROJETO CARROCEIRO DE IPORÃ
}

\section{Extension directed to horse and horseman: Horse wagon driver project - UFPR - Palotina and Iporã's horse wagon driver}

\section{Extensión dirigida al caballo y al trabajador: Proyecto del conductor del carro del caballo - UFPR - Palotina e Projecto conductor del carro del caballo de Iporã}

\author{
Erica Cristina B. P. Guirro ${ }^{1}$ \\ Ayrton Rodrigo Hilgert ${ }^{2}$ \\ Márcia Paula Ening ${ }^{2}$ \\ Simone Cerqueira Lima² \\ Aline Patrícia Munhoz ${ }^{2}$ \\ Camila Cecília Martin² \\ Gislaine de Fátima Carvalho² \\ Kleber Menegon Lemes²
}

\begin{abstract}
RESUMO
Os carroceiros transportam material reciclável, fretes e entulhos. Embora a saúde e qualidade de vida do animal utilizado reflitam na renda do proprietário, a maioria desses cavalos de tração não recebe assistência veterinária. Assim, foi implantado o Projeto Carroceiro - UFPR - Palotina para conhecer o perfil dos cavalos de tração e as necessidades dos carroceiros da região de Palotina. Posteriormente, criou-se o Projeto Carroceiro de Iporã/PR para garantir maior assistência aos cavalos e carroceiros desse município. Verificou-se que os principais problemas incluem falhas nutricionais, de casqueamento e afecções cutâneas. O próximo passo será tentar reduzir os problemas de ordem de trabalho como excesso de carga por frete, jornada de trabalho prolongada e pouca oportunidade de hidratação dos animais durante o trabalho.

Palavras-chave: carroceiro, cavalo.
\end{abstract}

\begin{abstract}
ABSTACT
Horse wagon drivers carry recycled material, freights and rubbles. Although animal's health and quality of life of animal reflect in the owner's income, majority of horses doesn't receive veterinary assistance. Thus, Horse wagon driver project - UFPR - Palotina was implanted in Palotina to know horse's profile and horse wagon driver's necessities. Later, Iporã's horse wagon driver project was created to guarantee greater assistance to the horses and horse wagon driver from Iporã. It was verified that the main problems include nutritional troubles, horseshoe fails and skin problems. Next step will be to try to reduce work problems as load excess for freight, hours of working drawn out and little chance of animal's hydration during work. Key-words: horse, horse wagon driver.
\end{abstract}

\footnotetext{
1 Professora Adjunta da UFPR / Palotina. E-mail: prof.erica.guirro@gmail.com. Autor para correspondência: UFPR, Rua Pioneiro, 2153, Palotina/PR, CEP: 85950-000.

2 Acadêmico da UFPR / Palotina.
} 


\section{RESUMEN}

Los conductores del carro del caballo llevan el material reciclado, cargas y escombros. Aunque la salud y calidad de vida del animal reflejen en la renta del dueño, la mayoría de caballos no recibe ayuda veterinaria. Así, el Proyecto del Conductor del Carro del Caballo - UFPR - Palotina fue implantado en Palotina para conecer las necesidades del trabajador y el caballo del caballo. Más adelante, el Proyecto del Conductor del Carro del Caballo de Iporã fue creado para garantizar mayor ayuda a los caballos y al conductor del carro del caballo de Iporã. Fue verificado que los mayores problemas incluyen apuros alimenticios, herradura falla y los problemas de piel. El paso siguiente será intentar reducir problemas del trabajo como exceso de peso por carga, las horas de trabajo dibujadas y poca ocasión de la hidración del animal durante trabajo. Palabras-clave: caballo, conductor del carro del caballo

\section{Introdução e Revisão de Literatura}

O cavalo tem importância histórica no desenvolvimento humano (DENOIX, 1994). Cavalo de tração é o equino com marcante capacidade de puxar pesadas cargas. Desde a domesticação, os equídeos de tração são considerados indispensáveis e são utilizados para diversos trabalhos, geralmente exigidos acima de seus limites naturais (MARANHÃO et al., 2006).

Atualmente, os cavalos de tração utilizados em carroças transportam material reciclável, fretes, mudanças, entre outros. Carroceiro é o indivíduo que conduz uma carroça geralmente puxada por cavalos. Na maioria das vezes, o condutor é o proprietário do animal e da carroça (ROMANSINI, 2005).

A região de Palotina conta com diferentes colonizações (IBGE, sem data). Nas cidades em que houve colonização gaúcha, formada por indivíduos oriundos de famílias italianas $e$ alemãs, quase não houve emprego de tração animal, como é o caso de Palotina, Maripá, Marechal Cândido Rondon e Toledo. Já nas cidades colonizadas por indivíduos vindos do sudeste do país, como Iporã, Franscisco Alves, Umuarama e Terra Roxa, há elevado número de cavalos de tração pelas ruas.

O desemprego aliado à falta de qualificação aumenta o índice de subempregos e, não raras vezes, observa-se o crescente número de lavouras de subsistência e do uso de animais de tração (MATSUO, 2009). Geralmente, os carroceiros têm situação socioeconômica desfavorável e, mesmo sabendo que os cavalos são importantes nesse contexto, não raras vezes tais animais são mantidos sob condições inadequadas, manejo incorreto e submetidos a falhas nutricionais significativas (MENEGATTI et al., 2010).

A criação de projetos que visem melhorar as condições de bem-estar animal pode beneficiar os equinos utilizados nesse tipo de trabalho e, consequentemente, melhorar a renda do carroceiro. Esse tipo de iniciativa pode ocorrer por meio da implantação de projetos de extensão universitária. A Universidade Federal do Paraná define "extensão Universitária como um processo educativo, cultural e científico que articula o ensino e a pesquisa de forma indissociável e viabiliza a relação transformadora entre a Universidade e os demais setores da sociedade" (Resolução no 70/08-CEPE).

Nesse contexto, diversas universidades brasileiras que têm curso de Medicina Veterinária se uniram às Prefeituras para implantar projetos "carroceiros", a fim de melhorar a qualidade de vida dos carroceiros e dos animais utilizados neste segmento. O Projeto Carroceiro da Universidade Federal de Minas Gerais orienta os carroceiros quanto ao manejo, bem-estar, alimentação e prevenção de doenças nestes animais. Ademais, permite cadastrar essa população e os animais utilizados, estimular associativismo dos carroceiros e integrar o aluno de graduação à realidade socioeconômica de Belo Horizonte ${ }^{3}$.

A Universidade Federal do Paraná em parceria com as prefeituras de Curitiba e Pinhais desenvolve o "Dia do Carroceiro", no qual ca-

\footnotetext{
3 Disponível em: <www.vet.ufmg.br/academicos/extensao-cenex/projetos-de-extensao/projeto-carroceiro>. Acesso em: $\mathrm{dd} / \mathrm{m} / \mathrm{aa}$.
}

Extensão em Foco, Curitiba, n. 7, p. 141-148, jan./jun. 2011. Editora UFPR 
valos de tração recebem assistência veterinária, são submetidos a exames físicos e exames laboratoriais, além de tratamento antiparasitário. Este serviço foi precedido de cadastramento dos carroceiros, informações sobre as condições de trabalho, manejo sanitário e nutricional dos cavalos ${ }^{4}$.

O Projeto Amigo do Carroceiro, em Lages/SC, é uma parceria entre o Centro de Vigilância Ambiental, a Coordenadoria do Bem-Estar Animal e a Universidade Estadual de Santa Catarina. São distribuídas cartilhas com informações sobre ensinamentos básicos de anatomia, nutrição e os principais cuidados que o carroceiro deve ter com seu animal. Ademais, este projeto presta serviços como exames clínicos, tratamento de enfermidades, fornecimento de alimentação aos cavalos, casqueamento $e$ ferrageamento, exames de fezes e vermifugação $e$, ainda, recebe e encaminha denúncias de maus tratos com os animais e distribui a cartilha "Carroceiro legal não maltrata o animal" que proporciona esclarecimento sobre como cuidar bem dos animais de tração. Um modelo semelhante de projeto está em implantação em Florianópolis ${ }^{6}$.

A Universidade Federal Rural da Amazônia também possui um Projeto Carroceiro com metas mais sociais e baseadas no desenvolvimento de um sistema de manejo de tração animal adaptado a uma sociedade justa e humana que integre o animal, o carroceiro e sua família. Os objetivos incluem melhorar a qualidade de vida do homem e do animal, incluir o carroceiro socialmente e legalizar essa profissão, dar alternativas para aumentar a renda, informar sobre biologia, manejo, bons tratos e demais cuidados requeridos pela espécie equina e fortalecer na região o curso de Medicina Veterinária por meio do atendimento clínico-cirúrgico ${ }^{7}$.

\footnotetext{
4 Disponível em: < www.curitiba.pr.gov.br>. Acesso em: dd/m/ aa.

5 Disponível em: <www.lages.sc.gov.br>. Acesso em: dd/m/ aa.

6 Disponível em: <www.pmf.sc.gov.br/bemestaranimal/projetos $>$. Acesso em: dd/m/aa.

7 Disponível em: <www.ufra.edu.br/cursosgraduacao/veteri-
} naria/projetos/proj_carroceiro.pdf $>$. Acesso em: dd/m/aa.
$\mathrm{O}$ atendimento veterinário regular de equinos é de fundamental importância para garantir que os animais mantenham sanidade adequada e possam exercer seu trabalho de maneira mais eficiente (SPEIRS, 1999). É possível que o clínico diagnostique inúmeras enfermidades e oriente o proprietário quanto as importantes mudanças de manejo a partir de aferições simples como auscultação da frequência cardíaca, frequência respiratória, avaliação da coloração das mucosas, auscultação da mobilidade intestinal, verificação de grau de hidratação, avaliação do escore corporal, exame visual cutâneo e dos cascos (FEITOSA, 2008).

Certamente, a criação de projeto de extensão voltado à assistência veterinária de cavalos de tração utilizados pelos carroceiros no oeste do Paraná certamente pode beneficiar um elevado número de animais e, consequentemente, promover maior ganho de renda para os proprietários. Dessa forma, este artigo visa relatar as experiências dos projetos de extensão universitária "Projeto Carroceiro - UFPR - Palotina" e "Projeto Carroceiro de Iporã", ambos idealizados por docentes do Campus Palotina da UFPR.

\section{Material e métodos}

Em 2009, após aprovação pela Pró-reitoria de Extensão e Cultura da Universidade Federal do Paraná, instituiu-se o projeto "Carroceiro - UFPR - Palotina" para se conhecer o perfil dos carroceiros e dos animais de tração utilizados na região de Palotina - PR; realizar atendimento veterinário aos animais de tração de Palotina e região; melhorar a relação entre os as proprietários dos animais de tração, os animais de tração e o Hospital Veterinário. Após exame clínico geral, os proprietários recebiam a prescrição para os animais e, ainda, orientações sobre a melhor forma de cuidar de seu cavalo. 
Foi realizado contato com a Prefeitura de Palotina e com as Prefeituras de cidades vizinhas a fim de agendar o "Dia do Carroceiro" em cada município. Definido o dia da visita, cabia à Prefeitura divulgar o dia e local do evento para que os carroceiros comparecessem juntamente com seus cavalos. Em Palotina, o evento foi realizado nas dependências do Hospital Veterinário do Campus Palotina da UFPR.

No "Dia do Carroceiro", os proprietários de animais de tração traziam seus cavalos para avaliação veterinária. Os exames clínicos eram realizados pelos acadêmicos previamente treinados, sob constante supervisão da coordenação do projeto e incluiu identificação, anamnese, exame físico e, eventualmente, exames complementares. $\mathrm{O}$ atendimento era gratuito $e$ cada Prefeitura doou os vermífugos necessários. Os demais fármacos prescritos deveriam ser adquiridos pelos proprietários nas casas agropecuárias da cidade.

Além disso, houve orientação sobre vacinação, necessidade de fornecer água de qualidade, inclusive durante o período de trabalho, e importância de se garantir alimento e sal mineral de qualidade em quantidade adequada. Além disso, foram dadas orientações sobre a jornada de trabalho ideal, necessidade de se fazer intervalos durante o trabalho, máximo de carga permitida por viagem, uso de arreio adequado, higiene diária, casqueamento, ferrageamento, melhor forma de condução da carroça, preparação do condutor e informações sobre o tráfego de carroças.

A cidade de Iporã foi a que melhor recebeu o projeto, inclusive foi onde houve mais visitas e maior número de animais atendidos. Os principais fatores que contribuíram pelo sucesso do projeto na cidade foram o envolvimento da Prefeitura e a ampla divulgação do projeto diretamente junto aos carroceiros. Assim, em Iporã ficou claro que a metodologia empregada foi adequada e atendeu um grupo de trabalhadores que carecia de cuidados e estava pronto para acatar recomendações.

Portanto, em 2010, o projeto inicial foi encerrado e, então, iniciou-se o projeto "Carroceiro de Iporã". Como o perfil dos carroceiros de Iporã e suas necessidades já eram conhecidos, esse novo projeto pretendia aprofundar o contato com uma população específica e garantir assistência veterinária regular.

\section{Resultados e discussão}

Em 2009, na vigência do projeto "Carroceiro - UFPR - Palotina", foi feito contato com as Prefeituras de 10 municípios, mas apenas três concordaram com a proposta, apesar de não haver custos para as Prefeituras. A principal alegação era de que não havia interesse, necessidade ou disponibilidade para esse tipo de atendimento. Talvez tivesse sido interessante que as Prefeituras apostassem na ideia pelo menos uma vez antes de recusá-la, mesmo porque era gratuita e possivelmente atenderia um público carente de valorização.

Foram realizadas sete visitas denominadas "Dia do Carroceiro" (Figura 1), sempre aos sábados à tarde, visto ser esse o dia e horário de maior disponibilidade para os carroceiros, já que de eles trabalham aos sábados até o meio-dia $e$, aos domingos, descansam. Foram atendidos 77 animais de 59 proprietários, visto que muitos proprietários possuíam diversos cavalos.

Indubitavelmente, os problemas sanitários e de manejo encontrados nas primeiras visitas foram maiores que nas visitas subsequentes $e$, possivelmente, isso se deva à ação do projeto e do ganho de consciência do proprietário em cuidar melhor de seu cavalo para garantir renda maior. O simples fato dos carroceiros perceberem que um grupo de universitários, professores e a Prefeitura estava se preocupando com eles e com seus cavalos já representava um motivo signifi- 
cativo para que eles mudassem velhos hábitos e tentassem seguir as orientações fornecidas nas visitas. de vida do animal, mesmo que isso representasse ganhos financeiros. Em outros casos, o cavalo era visto como peça extremamente importante

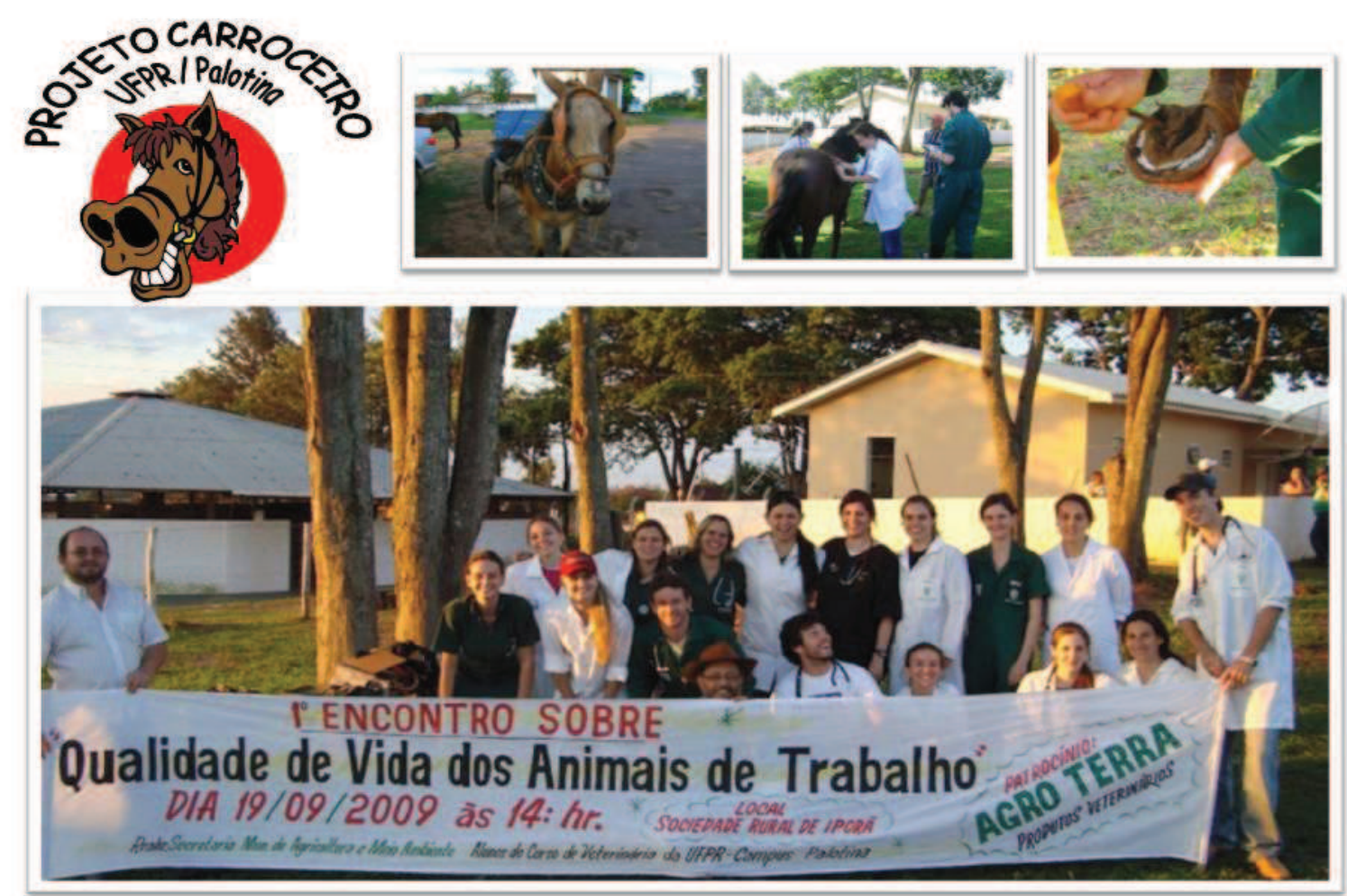

FIGURA 1 - EXECUÇÃO DO PROJETO DE EXTENSÃO "CARROCEIRO - UFPR - PALOTINA", EM 2009

A exibe a logomarca do projeto; $\mathrm{B}$ ilustra um animal de tração com os arreios normalmente utilizados durante o trabalho; $\mathrm{C}$ mostra os acadêmicos realizando exame clínico veterinário em animal de tração; D exibe limpeza de casco de cavalo portador de afecção podal; E ilustra o Secretário da Agricultura de Iporã (seta preta), a coordenadora do projeto (seta branca) e os acadêmicos participantes do projeto.

O projeto foi muito importante para conhecer os principais problemas enfrentados pelos carroceiros e pelos cavalos de tração da região de Palotina. Notou-se variação do nível de relação entre proprietário e cavalo, sendo que em alguns casos o animal era visto apenas como ferramenta e, nesses casos, era claro perceber que não havia interesse em melhorar a qualidade do trabalho e o proprietário alegava que prezava pela saúde e bem-estar, na medida do possível. Nesta segunda situação, os proprietários prestavam muita atenção nas prescrições, solicitavam retorno da visita e mostravam interesse em solucionar os problemas.

Houve crescimento de vários ângulos: os proprietários despertaram para a importância de cuidar bem de seus cavalos, já que isso poderia refletir em mais qualidade de trabalho $e$, consequentemente, maior possibilidade de renda familiar; as Prefeituras puderam estreitar a relação com esse foco da população $e$ foi observado que em alguns municípios o contato era estreito e amigável e, em outros, era fraco; houve crescimento dos integrantes do projeto que puderam vivenciar a vida dos carroceiros e conhecer a dificuldade dessa população. 


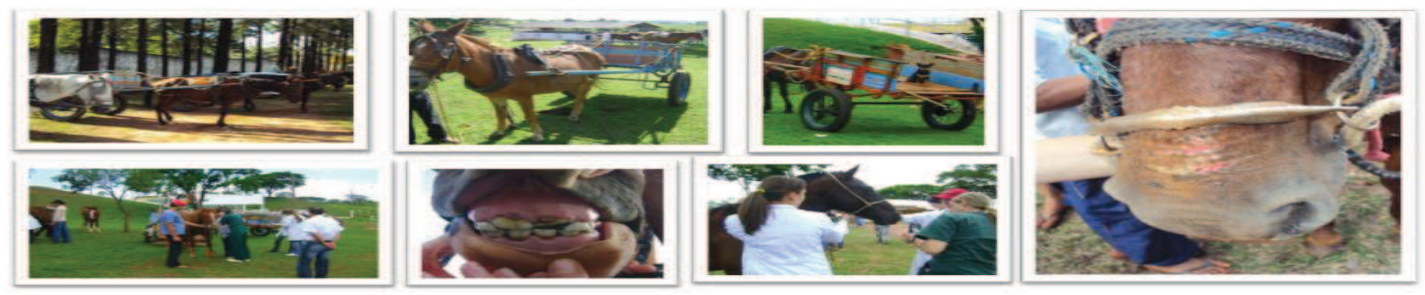

FIGURA 2 - EXECUÇÃO DO PROJETO DE EXTENSÃO "CARROCEIRO DE IPORÄ"

A metodologia foi válida, mas o resultado final em cada município dependeu da importância dada pela Prefeitura ao projeto. Nas cidades onde a Prefeitura não atentou para a iniciativa proposta, houve menor divulgação do dia de campo e, então, menos carroceiros trouxeram seus animais. Nas cidades em que a atenção foi maior, houve mais divulgação, o local agendado para o atendimento era mais adequado e de fácil acesso, a Prefeitura se preocupou em resolver parte dos problemas enfrentados pelos carroceiros e, assim, o retorno foi maior.

Com a criação do projeto "Carroceiro de Iporã" foi oferecido atendimento regular $e$, assim, verificou-se maiores mudanças. Desde sua implantação, foram realizadas seis visitas que totalizaram aproximadamente 180 atendimentos veterinários a equinos de 2 meses a 18 anos de idade, sendo a maioria entre 4 e 8 anos de idade. Esses animais pertenciam a cerca de 45 carroceiros, visto que alguns deles tinham mais de um cavalo, a fim de poder realizar rodízio para evitar sobrecarga de trabalho. A maioria dos carroceiros esteve presente em pelo menos quatro "Dia do Carroceiro" e muitos estiveram presentes em todas as visitas.

Os principais problemas apresentados pelos animais eram falhas de casqueamento, falha nutricional e problemas de pele. Houve atendimento veterinário adequado $e$ foram prescritos os cuidados necessários para melhoria da qualidade de vida dos animais. Aproveitou-se o momento para esclarecer que ao otimizar a saúde animal haveria reflexo positivo e direto na renda do carroceiro.

Além do exame clínico (Figura 2), os animais foram vermifugados e, conforme a necessidade, casqueados. Os principais problemas observados incluíram excesso de carga e jornada de trabalho, baixo escore corporal, falhas de casqueamento, afecções cutâneas e ectoparasitoses. Houve prescrição de medicamentos e orientações quanto ao tratamento de afecções. Atualmente, estão sendo implantadas placas de identificação das carroças e carteirinhas individuais de identificação dos animais (Figura 3).

A exibe animais de tração esperando pelo atendimento veterinário no "Dia do Carroceiro; $\mathrm{B}$ ilustra um animal de tração com os arreios normalmente utilizados no trabalho; $\mathrm{C}$ mostra a carroça; $\mathrm{D}$ exibe os acadêmicos realizando exame clínico veterinário em animal de tração; E ilustra a boca de um cavalo de tração com problemas odontológicos; F mostra acadêmicos vermifugando um equino; $G$ exibe ferimento cutâneo provocado por equipamento metálico utilizado no arreio de um cavalo de tração. 

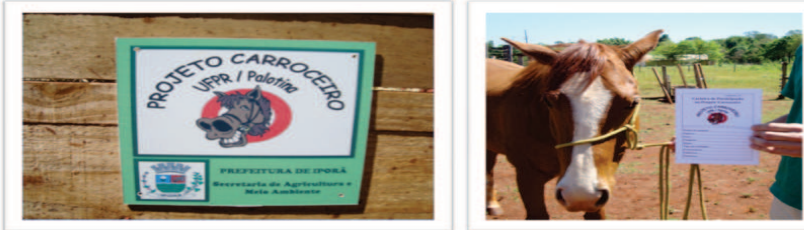

FIGURA 3 - PLACAS DE IDENTIFICAÇÃO DAS CARROÇAS (A) E CARTEIRINHAS INDIVIDUAIS DE IDENTIFICAÇÃO DOS ANIMAIS (B) IMPLANTADAS PELO PROJETO "CARROCEIRO DE IPORÃ

Os carroceiros mostraram-se satisfeitos com o atendimento veterinário e observou-se marcante ganho social, pois a maioria dos proprietários relatou que era a primeira vez que seu animal passava por avaliação veterinária e que isso evidenciava que seu trabalho era importante para a sociedade.

Quanto aos acadêmicos participantes dos projetos supracitados, notou-se evidente ganho de responsabilidade durante a execução das atividades previstas. Foi possível praticar "extensão" no sentido mais amplo da palavra durante o agendamento das visitas, atendimento aos animais e esclarecimento feito aos carroceiros, sempre sob supervisão da coordenação do projeto. A maioria dos graduandos relatou maior confiança na execução das tarefas práticas, maior responsabilidade social com sua futura profissão, melhor preparação para organização de eventos e segurança em se relacionar com os proprietários e com os responsáveis pelos órgãos municipais competentes.

\section{Conclusões}

Foi importante para os carroceiros sentirem-se valorizados e perceber que o "Dia do Carroceiro" era uma oportunidade de cuidar de seus animais e, com isso, melhorar suas condições de trabalho. Os cavalos de tração foram beneficiados pois receberam atendimento veterinário especializado e terapias de baixo custo que realmente poderam ser executadas. Houve ganho para o curso de Medicina Veterinária da UFPR/Palotina ao conhecer a população de carroceiros da região e suas principais carências e dificuldades e fim de tentar estreitar o relacionamento UFPR - comunidade externa. Assim, este tipo de iniciativa tem importante impacto social, mas requer continuidade para que objetivos sejam alcançados.

\section{REFERÊNCIAS}

CONFERÊNCIA ANUAL DA ASSOCIAÇÃO BRASILEIRA DOS MÉDICOS VETERINÁRIOS EQUINOS (ABRAVEQ), 11., 2010, São Paulo. "Amigo do Carroceiro" CAV-UDESC no município de Lages - SC: anais. São Paulo: Revista Brasileira de Medicina Veterinária Mais Equina, v. 29, supl. 1, p.1-8, 2010. Disponível em: < http://www.revistas. udesc.br/index.php/udescemacao/article/viewFile/2103/ pdf_54>. Acesso em 10/11/2010.

Carroceiros e bem-estar animal. Disponível em: <www. pmf.sc.gov.br/ bemestaranimal/projetos $>$. Acesso em: 10/12/2010.

DENOIX, J. M. Functional anatomy of tendons and ligaments in the distal limbs (manus and pes). Veterinary Clinics of North America: Equine Practice, v. 10, p. 273321, 1994

FEITOSA, F. L. F. Exame físico geral ou de rotina. In: Semiologia veterinária - a arte do diagnóstico. 2 ed. São Paulo: Roca, 2008. p.77-102.

IBGE. Palotina. Disponível em: < http://www.ibge.gov.br/ cidadesat $/$ painel $/$ painel. php?codmun $=411790>$. Acesso em 26/12/2010.

MARANHÃO, R. P. A.; PALHARES, M. S.; MELO, U. P.; REZENDE, H. H. C.; BRAGA, C. E.; SILVA FILHO, J. M.; VASCONCELOS, M. N. F. Afecções mais freqüentes do aparelho locomotor dos eqüídeos de tração no município de Belo Horizonte. Arquivos Brasileiros de Medicina Veterinária e Zootecnia, v. 58, n. 1, p. 21-27, 2006.

MATSUO, M. Trabalho informal e desemprego: desigualdades sociais. 2009. 384p. Tese (Doutorado em Sociologia) - Faculdade de Filosofia, Letras e Ciências Humanas, Universidade de São Paulo, São Paulo, 2009. 
Medicina veterinária social. Disponível em: <www.ufra. edu.br/cursosgraduacao/ veterinaria/projetos/proj_carroceiro.pdf $>$. Acesso em: 10/12/2010.

MENEGATTI, J.; LIMA, R. V. P.; PAOLINI, E.; FONTEQUE, J. H. Avaliação morfométrica de eqüinos de tração (carroceiro) pertencentes ao Projeto de Extensão Projeto Carroceiro da UFMG. 2010. Disponível em: <www.vet. ufmg.br/ academicos/extensao-cenex/projetos-de-extensao/projeto-carroceiro >. Acesso em: 10/12/2010.

Projeto Carroceiro em Curitiba. Disponível em: <www. curitiba.pr.gov.br>. Acesso em: 21/12/2010.

Resolução n 70/08-CEPE. Disponível em: <http://www. proec.ufpr.br/ downloads/extensao/cepe70.08.pdf $>$. Acesso em 16/10/2011.

ROMANSINI, S. R. M. O catador de resíduos sólidos recicláveis no contexto da sociedade moderna. 2005. 90p. Dissertação (Mestrado em Ciências Ambientais) - Universidade do Extremo Sul Catarinense, Criciúma, 2005.

SPEIRS, V. C. Exame Clínico de Eqüinos. Porto Alegre: Artmed, 1999. 274p. 